\title{
A new pyrometer
}

\section{Pouillet}

To cite this article: M. Pouillet (1829) A new pyrometer, Philosophical Magazine Series 2, 6:34, 312-312, DOI: $10.1080 / 14786442908675150$

To link to this article: http://dx.doi.org/10.1080/14786442908675150

曲 Published online: 14 Jul 2009.

Submit your article to this journal

Џ Article views: 3

Q View related articles $₫$ 
PREPARATION OF UREA, BY M. HENRY, JUN.

Add a slight excess of subacetate or hydrate of lead to fresh urine; the precipitate contains the salts' formed by the union of the metallic oxide with the acids of the salts of the urine, and a compound produced by the combination of the mucus and a great part of the animal matter, with the hydrate or subsalt employed *.

The decanted fluid is treated with diluted sulphuric acid slightly in excess, to separate all the lead, and to act afterwards during evaporation upon the acetates of soda and lime which may be formed. After having separated the white precipitate, the liquid is quickly evaporated, and unimal charcoal added during ebullition. When the fluid is clear, it is to be strained through a fine cloth, and evaporated to about one third of its butk; on cooling, the liquor frequently becomes a yellowish acicular crystalline mass, consisting of much urea and" some saits. The crystals when drained and pressed are to be added to those produced by evaporating the mother water, also simiTarly treated; being thus deprived of the brown viscous matter which enveloped them, the crystals are to be treated with a small quantity of carbonate of soda, to decompose any acetate of lime which may remain, and they are then to be digested in alcohol; the solution fltered and distilled leaves urea, which may be re-crystallized by solution in water and evaporation.-Journal de Pharmacie, April, 1829.

\section{A NEW, PYROMETER, BY M. POUILLET.}

This instrument is an oval vessel of platina, soldered to a tube of the same metal of known capacity : this vessel communicates with a graduated tube, so that the increase of volume occasioned by the rise of temperature may be immediately read. To use this pyrometer, the platina vessel is to be placed in the furnace, the temperature of which is to be known; the original volume of the air or gas contained in the instrument being known, the temperature is determined by the inerease of its volume, $-l$ lbid.

\section{POISONING BY CHEESE.}

Dr. H. L. Westrumb of- Harneln, fonnd that seven persons were poisoned by decayed or damaged cheese (fromage passé, fromage gâté). M. Sertüner analysed this cheese and found in it a peculiar acid, which appeared bath-to him: and to $M$. Westrumb to be the poisonous principle; the anatysis was performed with ether and alcohol. Three_different substances were obtained from the cheese : viz.

Ist. Caseate of ammonia.

2 dly. An acid fatty, or resinous cheesy, matter.

3 dly. An acid bat less fatty matter.

These substances, tried separately upon dogs and cats, showed that the first was the. least:poisonous, the third more so, and the second the most poisonous of all. The symptoms occasioned by the poison

* 'This deposit, well washed and treated while hot with solution of carboriote of potash, yields a liquid, from which a large quantity of uric acid may be precipitated by excess of muriatic acid. 